\title{
El modelo del homo tragicus desde lo pragmático semiótico
}

\author{
Marta Susana López
}

\section{Introducción}

Es mi propósito en este artículo, establecer ciertas relaciones epistemológicas entre la semiótica y las otras ciencias sociales, en particular, la sociología, tomando como herramienta el modelo de acción trágica propuesto por Ramón Torre (1999). De estas relaciones, resultarán - a mi modo de ver- interesantes paralelismos entre las respectivas evoluciones de ambas ciencias.

La artificial clasificación de las diversas disciplinas contribuye a crear un sistema simplificante de la percepción de lo real. Una manera de comenzar a romper con este sistema todavia vigente es reconocer los límites del conocimiento humano para entonces acceder a la complejidad de lo cognoscible. Tales límites están determinados fundamentalmente por los signos que vinculan la mirada del hombre con el mundo. Porque no hay conocimiento que no esté mediado y, a la vez, mediatizado por los signos, sus sistemas y sus combinaciones, en el más extenso sentido del término: palabras, frases, textos; teorías, modelos, paradigmas; mitos, religiones; en fin, ideologías. (Morin, E., 1992; Peirce 1987). El reconocimiento, la valoración y el análisis del papel mediador y mediatizador de los signos es imprescindible para reconocer la complejidad de todo objeto de estudio, en particular los construidos por las ciencias humanas.

Como ciencia de los signos y de su funcionamiento, la semiótica parece ser la ciencia humana instrumental por excelencia, dado que son esenciales al hombre la búsqueda y el hallazgo conscientes de los significados, sin los cuales la vida como tal -en tanto ser humanose le presentaría como un absurdo. Es más: creo que es posible aceptar que la semiótica constituye una de las disciplinas -al igual que la lógica, la cibernética y la estadística- destinada a sustentar epistemológica y metodológicamente tanto a las ciencias naturales como a las del hombre.

Por su parte, la sociología clásica concibió su objeto de estudio como una sociedad totalizadora y ordenada (pero al mismo tiempo 'en movimiento') de individuos interdependientes, potencial o efectivamente semejantes. En ello, adquiere especial relevancia el concepto de solidaridad social. Esta postura epistemológica deriva de la teoría de Emile Durkheim y se apoya en algunos presupuestos como lo son: la creencia en la ciencia como herramienta eficaz para la investigación del fenómeno social, lo cual conduce a la institucionalidad académica de las ciencias sociales; la creencia (casi nunca verificada empíricamente) en la existencia de un "consenso normativo" para regular la conflictividad social; y la confianza en las competencias integradoras de una serie de instituciones, como la del Estado, y otras.

Desde los afios 70 del siglo XX, comienzan a aparecer los signos de "disolución" de tales instituciones, expresión del comienzo de la "crisis". Mientras, en la comunidad académica de las ciencias sociales se empieza a advertir la insuficiencia de los sistemas conceptuales con las que hasta ese entonces se había contado. Pablo De Marinis (1999) plantea la hipótesis de que la serie sujeto - comunidad - sociedad - Estado pierde actualmente el orden y la estabilidad que aparentaba poseer. Nacen asf teorias que tematizan el cambio en los órdenes 
sociales, en las modalidades de articulación del individuo y la sociedad, de la sociedad con el Estado, y de las concepciones de la subjetividad. De ahí que la meta de nuestro trabajo sea también la de pensar acerca de la verdadera misión de las ciencias sociales y humanas en una era que algunos denominan 'postsocial". Ello implica intentar la reflexión y la çrítica de las ciencias sociales sobre sí mismas.

\section{La acción trágica como modelo epistemológico en la autocrítica de las ciencias sociales}

Pretendo realizar este abordaje considerando la problemática del sujeto mediante conceptualizaciones diferentes de las que se encuentran actualmente en vigencia en los ámbitos académicos, mediáticos y dirigenciales. Específicamente, como ya adelantara, tomaré el análisis de "Homo tragicus", de Ramón Ramos Torre. A mi modo de ver, Ramos Torre adopta una actitud pragmático-semiótica para aplicarla a la reflexión sociológica: anólisis de textos y análisis de los análisis, en la búsqueda de "esquemas prácticos" de acción, valiéndose del modelo otorgado por la tragedia griega. Este tipo de investigación -según entiendo- se acerca a los objetivos propios de la pragmática semiótica. Desde uno de sus enfoques, el de la semiótica greimasiana, ella persigue la comprensión de la estructura general de la acción humana a través de la estructura de los relatos. Desde otra perspectiva, no incompatible, sino complementaria, a través del funcionamiento lógico de los signos, la semiótica peirceana, también constituye una semiótica de la acción. Me parece que el trabajo de Ramos Torre no sólo constituye una búsqueda de nuevas herramientas conceptuales que pueden ser útiles para comprender al actor social de nuestros tiempos, sino también un claro ejercicio de indagación epistemológica y metodológica que lo conduce hacia el hombre y su praxis a través de determinados textos, como los literarios, en este caso. Mi propósito es básicamente contribuir a fundamentar y justificar epistemológica y metodológicamente esta idea que Ramos Torre califica, quizás con excesiva modestia, de "intuición".

En relación con la reflexión de las ciencias sobre sí mismas, Latour, B. (1992), citado por Wallerstein I. $(1999 ; 45)$ - propugna "la superación de la segmentación académica y social de la realidad en las tres categorias de naturaleza, politica y discurso". Por el contrario, para el, "las redes de la realidad son simultáneamente reales como la naturaleza; narradas como el discurso y colectivas como la sociedad". (Ibid;49) .

Por mi parte agrego que, efectivamente, la naturaleza y la cultura, en lugar de ser consideradas términos de una oposición irreductible, deberían ser vistas como unidas por su semioticidad. De acuerdo con los sociólogos mencionados, sostengo que es tan potencialmente semiótica cualquier acción humana como todo texto o discurso. ¿Qué quiero decir con algo "potencialmente semiótico"? Me refiero a todo aquello capaz de adquirir (siéndole adjudicado por un interpretante) algún significado (Peirce, Ch. 1987). Agrego, además, que no existe fenómeno social sin dimensión semiótica, ni fenómeno semiótico que no sea social. Esto quiere decir que, cuando se considera un hecho como social, es porque previamente se ha manifestado sígnicamente y ha sido semantizado e interpretado por una sociedad (o parte de ella). (Verón, E. 1987; Magarifios de Morentin 1996).

Paso ahora a fundamentar lo dicho con los mismos argumentos desarrollados por Ramos Torre y Wallerstein. 
El primero de estos autores reconoce en el texto trágico el tipo de signo que lo puede llevar a comprender la acción humana en toda su complejidad actual. Sostiene que el objetivo de las ciencias sociales es, precisamente, el de "descomplejizar" la realidad, es decir, hacerla inteligible. El principal desafio para lograr esta meta es el de comprender la acción humana.

En tanto teoría de la acción, la teoría social ha producido a lo largo del tiempo ciertos modelos, ciertas "antropologías primarias", que este autor pretende ampliar reconceptualizando la acción a partir del "material estratégico" que le proporcionan los textos de la tragedia griega clásica (Siglo V a C). Encara entonces en su ensayo la búsqueda de "aspectos de la acción de relevancia analítica general $y$, por ello, actual", es decir, aspira a lograr "esquemas prácticos" generalizables (Ramos Torre 1999; $214^{!}$.

Este

autor afirma la relevancia sociológica de toda la literatura, pero da razones por las cuales presta atención especial a la tragedia:

- Constituye en sí misma la representación de la acción. Ésta es el centro y razón de ser de la tragedia;

- En ella, la acción es la "modeladora" del actor mismo.

Aquí la cuestión moral no es el núcleo de la acción. La tragedia se inserta en la problematicidad del encuentro de dos "universos prácticos", el del antiguo derecho gentilicio y el del nuevo derecho de la polis democrática. "El mundo trágico se puede asi convertir en un laboratorio para pensar la complejidad que demanda en la actualidad una teoría operativa de la acción" (Ramos Torre; 215).

Siguiendo la línea interpretativa de Aristóteles en su Poética, a Ramos Torre le interesan el modo y los resultados con que la tragedia aborda el mundo genérico (no sólo ético) de la acción. La tragedia representa "la imitación de una acción". Lo más importante es la estructuración de los hechos (pragmaton systasis), es decir, el mito (fábula o trama). Destaca que los aspectos relevantes de la trama trágica, en el análisis de Aristóteles, son los siguientes:

1.El objeto de la imitación trágica es la acción. Lo que interesa es lo que se hace.

2. La meta de los que protagonizan tal acción es la obtención de la eudaimonia, la cual sólo es posible actuando en el mundo. "Siendo la eudaimonia una praxis, su consecución o pérdida es consecuencia de la acción, no un estado de una carácter extraño a (o independiente de) la acción." (Ramos Torre 1999; 222)

Por lo tanto, los personajes y su carácter derivan de la acción, de lo que hacen (no a la inversa). Es decir, la subjetividad se construye en y por la praxis.

Y como dije más arriba, la intención de Ramos Torre es la de ampliar el número de los modos de concebir al hombre. Existen hasta ahora, según él, tres modelos dominantes (o "antropologías básicas"):

1.La del homo moralis, construida por Durkheim, a partir de de Kant y que continúa en Parsons y el estructural funcionalismo. Se trata de un sujeto moral que actúa de acuerdo a normas, códigos incorporados a lo largo de su praxis. Constituye un sujeto normativo.

2. La del homo rationalis, derivado del modelo económico. Es un sujeto que actúa según cálculos y preferencias, siempre para obtener el mayor beneficio, de acuerdo con leyes deterministas y estadísticas.

3. La del homo specularis, que actúa persiguiendo el reconocimiento, guiado por una imagen especular construida por los otros. Este modelo se deriva de A. Smith y tiene su continuación en Mead y en Goffiman. 
La ventaja estratégica del modelo del homo tragicus, parece ser la de implicar una mayor complejidad en el mundo, en la acción y en el actor, para abordar nuestra realidad actual, aparentemente inasible mediante los modelos tradicionales. En esta línea de pensamiento, Ramos Torre propone tres problemas por considerar en trabajos futuros:

1.cómo pasar de lo que por el momento es una mera intuición a una teoría operativa de la: acción.

2.saber porqué se desechó el modelo literario de lo trágico y cuáles fueron sus consecuencias.

3. Cómo analizar la complejidad actual (globalización, riesgo, reflexividad) desde el concepto de homo tragicus. (Ramos Torre 1999; 236-7)

Me parece necesario el desarrollo de alguna de estas cuestiones para comprender la postura de Ramos Torre. En este artículo', me propongo atender primordialmente a la segunda pregunta: saber porqué se desechó el modelo literario de lo trágico y cuáles fueron sus consecuencias. Mi hipótesis es que la teoría social no hizo sino seguir la evolución contemporánea de las otras ciencias sociales. Me refiero en particular a la linguística y a la teoría literaria derivada de los modelos linguísticos, así como a la semiótica estructuralista.

\section{Dos hermanas: la sociología de Durkheim y la lingüística de Saussure}

El modelo del homo moralis se corresponde coherentemente con el modelo de lengua y de hablante del estructuralismo desarrollado a partir de Saussure.

La sociología clásica (Durkheim, Weber, etc.) se caracteriza por una serie de ideasfuerza. Entre ellas la concepción de la sociedad como

(...) un todo orgánico, superior (y exterior) a los individuos que la componen, unificado en sus elementos por valores que le dan cohesión y estabilidad y que proporcionan sustento a las normas que reglan la conducta de los individuos y a las instituciones en las que esas conductas se desenvuelven. Si esos valores, esas normas y esas instituciones se alteran, la sociedad entrará en un proceso de desgarramiento y de desintegración. El tema central es, pues, el orden social; el cambio, la transformación sólo será un caso especial, controlado, del equilibrio, postulado simultáneamente como punto de arranque metodológico para el estudio científico de la sociedad y como ideal al que debe tender la humanidad. Para Durkheim, el orden moral es, (...) equivalente al orden social. Este a su vez, se expresa como un sistema de normas que, por su parte, se constituyen en instituciones. La sociología es el análisis de las instituciones; de la relación de los individuos con ellas. Portantiero J.C. 1977;16, 23-24).

Y| en efecto, Durkheim mismo afirma: 
Las maneras colectivas de obrar o de pensar tienen una realidad independiente de la de los individuos, la cual se conforma a aquélla en todos los momentos. Son cosas que tienen su existencia propia. El individuo las encuentra completamente formadas, y no puede hacer que no sean o que sean de otra manera de lo que son; está, pues, obligado a tenerlas en cuenta, y le es tanto más difícil (no decimos imposible) modificarlas, en cuanto, en grados diversos, participan de la supremacía material y moral que la sociedad tiene sobre sus miembros. Claro está, que el individuo interviene en su génesis, pero para que exista un hecho social, es preciso que muchos individuos hayan, por lo menos, combinado su acción, y que de esta combinación se haya engendrado algún producto nuevo. Y como esta sintesis se realiza fuera de nosotros (pues entran en ella una pluralidad de conciencias), tiene necesariamente por efecto el fijar, el instituir fuera de nosotros, determinadas maneras de obrar y determinados juicios, que no dependen de cada voluntad particular tomada separadamente. (...) existe una palabra, que amplificando un poco su sentido ordinario, expresa bastante bien esta manera de ser muy especial; nos referimos a la palabra institución. Sin desnaturalizar el sentido de esta expresión, se puede, en efecto llamar institución, a todas las creencias y a todas las formas de conducta instituidas por la colectividad; la sociologia podría, por tanto, definirse como la ciencia de las instituciones, de su génesis y de su funcionamiento" (Durkheim 1977:44).

Por lo tanto, el principio básico de la teoría de Durkheim es el de la realidad objetiva de los hechos sociales, los cuales tienen "una manera de ser constante, una naturaleza que no depende del arbitrio individual y de la cual derivan relaciones necesarias" (Ibid.; 45)

Por su parte, Saussure, en su intento -similar y contemporáneo al de Durkheim- de definir el objeto de estudio de la linguística, advierte que el lenguaje es un fenómeno heteróclito en el que es posible reconocer diversas dicotomias, por las cuales se forman las oposiciones: articulatorio/fónico; sonido/idea; significante/significado; sistema establecido (sincronía)/sistema en evolución (diacronía), etc. Una de las más determinantes es la que opone el aspecto individual al aspecto social. En sintesis, el lenguaje es un fenómeno imposible de ser estudiado en toda su complejidad tal como se presenta al investigador. Es por ello que Saussure adoptó una decisión metodológica por la cual instituyó la lengua como el objeto de la lingaística separándola del habla, sosteniendo que no era posible encarar el estudio de esta última en el estado de la ciencia de su época. Define entonces la lengua mediante diversas afirmaciones que implican, al mismo tiempo, una definición del habla, cuyo estudio queda así relegado:

- "La lengua es a la vez un producto social de la facultad del lenguaje y un conjunto de convenciones necesarias, adoptadas por el cuerpo social para permitir el ejercicio de dicha facultad en los individuos". (Saussure 1976; 62)

- "La lengua (...) es en si misma una totalidad y un principio de clasificación. Desde el momento en que le damos el primer lugar entre los hechos de lenguaje, introducimos un orden natural' en un conjunto que no se presta a ninguna otra clasificación." (Ibíd.; 62) 
- La lengua es una institución social: "es una convención y la naturaleza del signo en "que se conviene és indiferente." (Ibíd.; 63)

-No es el lenguaje hablado el natural al hombre, sino la facultad de constituir una lengua, es decir...

- ...un sistema de signos distintos que corresponden a ideas distintas." (Ibid.; 63)

- La lengua es "cristalización social", "producto social", "vínculo social" constituido por la suma de las imágenes verbales acumuladas en todos los individuos.(...) Es un tesoro depositado por la práctica del habla en los sujetos que pertenecen a una misma comunidad, un sistema gramatical que existe virtualmente en cada cerebro, o más exactamente en los cerebros de un conjunto de individuos, pues la lengua no esta completa en ninguno, sólo existe perfectamente en la masa.

- "La lengua no es una función del sujeto hablante, sino el producto que el individuo registra pasivamente; nunca supone premeditación (...") (Ibid.; 66).

- "Es la parte social del lenguaje, exterior al individuo, que por si solo no puede ni crearla ni modificarla; sólo existe en virtud de una especie de contrato establecido entre los miembros de la comunidad. " (Ibid.; 67).

- "La lengua es un sistema de puros valores que nada determina fuera del estado momentáneo de sus términos". (Ibíd.99)

El habla, por lo tanto, es el acto individual y voluntario por el cual el sistema (reglas y funciones) de la lengua se pone en uso. En otras palabras: El habla (y su resultado, el texto) es la actualización del sistema linguístico. El habla como texto o discurso no es tomada como objeto por la linguística hasta la segunda mitad del S XX, cuando se incorporan otros niveles de análisis: el de la semántica y el de la pragmática.

El paralelismo conceptual de Saussure y Durkheim se hace evidente. José Sazbón (1976) lo sintetiza diciendo:

El enfoque sociológico de su concepción de la lengua (la de Saussure) tiene muchos aspectos coincidentes con la doctrina de Durkheim: en uno y en otro la institución social actúa como una norma impuesta a la colectividad; la coerción que ejerce y la autonomía de que goza son sus características centrales. El individuo registra pasivamente $-y$ actualiza con sus actos-el funcionamiento de un sistema cuya dinámica es independiente de su arbitrio" (Sazbón 1976; 16).

Verón,E. (1987) sitúa el Curso de Lingüística General de Saussure en el marco del positivismo metodológico, dadas las dos propiedades indisolubles de los signos linguísticos: el de ser arbitrarios y el de ser involuntarios: "Este vínculo satisface bajo una nueva forma, el objetivo paradbjico que ha sido siempre el del positivismo: lo social se separa de lo natural por medio de lo arbitrario, para volver a unirse a él por medio de lo involuntario"(Verón 1987; 64). "La necesidad (como opuesta a lo arbitrario), perdida en el plano de las unidades (los signos) puede ser reencontrada en el conjunto, en el nivel del sistema. "(Ibid.; 72) En sociología, ocurre otro tanto sobre la base de la formulación paradójica positivista: "naturalizar lo social moralizándolo". (Ibid.; 63) 
Es decir, la sociología nace positivista no sólo en el sentido de que aspira a constituirse en disciplina científica tal como las ciencias naturales, sino como reacción contra el negativismo (postura crítica de la realidad) iluminista. Porque el sometimiento de la ciencia a los hechos como "datos" implica, en cierto sentido, una actitud de aceptación de "lo dado" como natural. (Portantiero 1977)

De esta manera queda conformado el modelo del homo moralis, del sujeto normatizado tanto social como linguísticamente, que actúa según reglas heredadas institucionalmente e incorporadas en su aprendizaje. Se trata de un modelo que permite hacer orden en el caos de la realidad, simplificándola, relegando lo complejo para más adelante, o negándolo. El hombre, como objeto de estudio, es "liberado" de las leyes de la naturaleza, pero es "sometido" a los sistemas institucionales en cuyo ámbito debe actuar.

La lengua sufre sin cesar la influencia de todos. Este hecho capital basta para mostrar la imposibilidad de una revolución. La lengua es, entre todas las instituciones sociales, aquella en que las iniciativas encuentran menos asidero. Está integrada a la masa social, y siendo ésta naturalmente inerte, aparece ante todo como un factor de conservación. (...) En todo instante, la solidaridad con el pasado predomina sobre la libertad de elección (...). Por ser el signo arbitrario no conoce otra ley que la de la tradición, y por fundarse en la tradición puede ser arbitrario"(Saussure 1976: 93).

Por su parte, Durkheim había dicho: "una creencia o una práctica social puede existir independiente de sus expresiones individuales" (Durkheim 1977;74)

Finalmente, en la semiología estructuralista heredera de Saussure, Louis Hjelmslev (1980) nos dice: "La meta de la teoria lingúística es probar, en lo que parece un objeto altamente invitador, la tesis de que todo proceso (inguístico en particular y social en general) tiene un sistema subyacente - -y toda fluctuación una constancia subyacente" (Hjelmslev 1980; 21).

\section{La semiótica greimasiana: una semiótica de la acción humana}

Por su parte, la semiótica estructuralista greimasiana, derivada de la perspectiva sistémica de Saussure y de Hjelmslev, construye su objeto, el significado, con miras a evitar el recurso a la intuición asimilada al subjetivismo. "El sentido no es solamente sentido individual sino también sentido en circulación" (Hénault 1979; 8). Posee entonces "una doble naturaleza:

- naturaleza individual subjetiva y particular por la parte de sentido percibida por el individuo solo: intuición dialectal o sentimiento lingulístico;

- naturaleza social, objetiva y solidaria por la parte de sentido en circulación o sentido común. Se la llama "conciencia semiótica" o "solidaridad semántica". La objetividad en lingaística es vista, de acuerdo B. Portier, como la coincidencia de las subjetividades. Una de las claves de la semiótica, dice Anne Hénault, es la de erigirse en "una tentativa de estructuración sistemática de la conciencia semiológica", sin importar demasiado la delimitación disciplinaria. Se aboga, por el contrario por el abordaje interdisciplinario. La 
semiótica se siente con derecho a operar por 'bricolage' y amalgamar conceptos y procedimientos de descubrimiento de origenes diversos." (Ibid.;9-11)

La semiótica greimasiana, además, se constituye en denuncia del empirisino espontanefsta e intuitivo respecto de las significaciones. Tiene como meta el estudio de éstas en cualquier dimensión, desde el sintagma, pasando por el texto hasta llegar al "saber compartido" de una determinada comunidad.

Observamos aquí que, respecto de la teoría saussureana, la unidad se expande y complejiza. Desde la lengua como sistema de signos, pasamos al texto como estructura inmanente. La semiótica de Greimas analiza precisamente los elementos esenciales del relato, en distintos niveles. Llega a constituirse en una semiótica de la acción humana, habiéndose basado para ello en los estudios de Vladimir Propp, formalista ruso, acerca de más de cien cuentos infantiles, en cuyas acciones Propp habia detectado invariantes básicas.

Las categorías de análisis asumen la tarea de dar cuenta de la sintaxis inmanente de todos los mensajes dinámicos. "Se trata aqui de una verdadera radiografia de la colmena humana" (Ibid..;45). En las llamadas programaciones narrativas, "uno se ve impulsado a leer experimentalmente, en la profundidad misma del lenguaje, una memorización de los principales esquemas de interacciones sociales y de lo que constituye el 'sentido humano'. (75)

Ramos Torre $(1999 ; 214)$, por su parte, dice: "La literatura me parece relevante porque en sus ficciones exploratorias de mundos humanos posibles proporciona un riquísimo material sobre la acción". Asi la reduce a "esquemas de sentido", sin "diseccionarla" teóricamente. Pero Hénault afirma que este proceso constantemente disponible no proviene de una actitud 'literaria'. Traduce las restricciones más profundas de la expresividad ordinaria: "simplemente el hombre no dispone de otros esquemas para figurar su acción sobre el mundo" (Hénault 1979; 77).

De este modo y paulatinamente, el estructuralismo ortodoxo de base inmanente -que reconocía sólo como analizables los niveles sintáctico y semántico- ha ido incorporando desde entonces nociones teóricas complejizantes que contribuyen en parte a construir una semiótica de la acción, es decir, agregando un nivel pragmático abarcador de los otros dos. Por su parte, la semiótica peirceana, ya de por sí, de base pragmática, es una lógica de la acción, "especialmente - dice Parret (1993)- la acción en discurso reflexivo".

Por todo lo dicho, me parece que, cuando Ramos Torre propone el esquema de la acción trágica como modelo para la comprensión de la realidad actual, epistemológica y metodológicamente está optando por una "actitud semiótico-pragmática" complejizante (es decir, apta para reconocer y comprender la complejidad) que reconoce en determinados textos (en este caso la tragedia) elementos útiles para comprender la acción del hombre en el mundo.

Parret (1993) considera que esta actitud pragmática se caracteriza por el reconocimiento de algunos aspectos esenciales como los siguientes:

- La subjetividad: ella habla sido "puesta entre paréntesis" (al modo de Lacan, Levi Strauss y de Foucault en su momento) por las ciencias sociales. Tener en cuenta al sujeto era incurrir en "historicismo", o en "psicologismo". Los factores que contribuyeron a este "desconocimiento" del sujeto fueron la concepción del mundo como un objeto o como un fenómeno, el predominio de la semántica formal bipolar y la actitud dicotomizante propia del pensamiento occidental (en Saussure, por ejemplo, lengua /habla, significado/significante). El sujeto, en todo caso era efecto de la estructura y no impulsor y fuente de estructuración. Con Emile Benveniste (1971) comienza la consideración del sujeto como "principio organizacional 
del lenguaje", lo cual implica una revalorización y renacimiento de la subjetividad. Posteriormente, a través de la "competencia modal", agregada al estructuralismo greimasiano, el análisis se complejiza, introduciendo una dimensión esencial de la subjetividad. La competencia modal "puede describirse como una organización jerárquica de modalidades' (estará basada, por ejemplo, en un querer-hacer 0 un deber-hacer que rigen un poder-hacer 0 un saber-hacer)" (Greimas 1982:69).

b- La racionalidad: al contrario del positivismo, el sujeto semiótico se convierte, como vemos, en el principio organizacional de un programa narrativo, deja de ser un elemento externo a la semiosis. La competencia del sujeto (el "saber cómo hacer") lo constituye como actante 0 actor. Relacionado con el saber-cómo-hacer (el contenido de la competencia), está el "tener-que-ser", es decir, "un sistema de restricciones que genera programas de acción." (Parret 1993:167). A partir del giro pragmático de la semiótica, se ha extendido el campo de investigación: de los textos literarios a los científicos, de los mundos culturales a los naturales. Parret propone un paso más para que la disciplina pueda efectivamente servir a las ciencias sociales. Acude a la ampliación y complejización del tratamiento de la deixis'. Al no ser ella un fenómeno puramente gramatical, sino con implicancias ideológicas, debiera convertirse el nosotros -ausente en la semiótica corriente- en el fundamento de la deictica, propendiendo así a una noción semiótica de solidaridad, de subjetividad comunal. La competencia modalizante del sujeto sería entonces considerada intersubjetiva, antes que subjetiva.

Por todo lo dicho, creo que la pragmática semiótica puede resultar particularmente operativa para la explicación de los aspectos dilemáticos y paradojales del homo tragicus, apuntados por Ramos Torre. El sujeto semiótico se convierte en actor y su naturaleza pasa a depender de la función que cumple en el programa narrativo, de la misma manera que el homo tragicus - de acuerdo con Ramos Torre- es el producto de su acción. La subjetividad aparece no por análisis (del texto), sino por catálisis, es decir, infiriéndola a partir del contexto que le otorga la acción. El homo tragicus se hace dificil de explicar y de comprender sin una concepción de la subjetividad, de la racionalidad, de la modalidad y la deixis como bases esenciales de la pragmática semiótica.

Por su parte Ramos Torre caracteriza a la acción trágica con algunos de los caracteres que se relacionan con los arriba enumerados para la acción social: precario.

1. Es ilimitada: rebasa los límites de su situación de origen y rompe con un equilibrio

2. Por lo anterior, es impredictible. No puede saberse los efectos que finalmente pone en movimiento.

3. Es irreversible. No hay "vuelta atrás", no puede des-hacerse.

Los siguientes, en cambio, son propios de la acción trágica:

4. Es dilemática: produce una situación paradojal, de doble vínculo, en el sentido de Watszlawick (1989) y Bateson (1999). Este es el tipo de factor que puede llevar a un individuo o a una sociedad entera hacia la esquizofrenia (López 1993). afectadas.

5. Es agonal: hay conflicto sin reconciliación hasta la destrucción recíproca de las partes

6. Existe oposición de elementos simétricos que mimetizan recíprocamente sus acciones: responde a una acción exactamente con el mismo tipo de acción. Lo simétrico es lo opuesto a lo 
complementario. En este último caso, hay dos posiciones distintas: la superior o primaria y la inferior o secundaria. En una relación simétrica, existe el peligro de la competencia, de la "escalada" para elevarse por sobre el otro, es decir se establece una especie de lucha en donde se tiende al rechazo del yo del otro. En la tragedia se tiende a la destrucción recíproca.

Aquí reside, creo yo, una de las diferencias fundamentales con los enfoques epistemológico-metodológicos de Saussure y de Durkheim: la consideración del texto y su asimilación a la acción humana se contraponen a la óptica restrictiva del estudio inmanente de los sistemas sociales, tanto lingüústicos como institucionales concebidos ellos como "heredados", "impuestos", paradojalmente, casi "naturalizados". Por el contrario, la consideración del proceso y de los textos tanto como la concepción de la acción (como texto) introducen -como vimos- la subjetividad, la imprevisibilidad de sus efectos, la duda sobre las motivaciones y las intenciones que los generaron. En fin, -según creo- la necesidad de la metodología interpretativa, en el marco de un paradigma pragmático semiótico.

No significa esto que los sistemas y las instituciones deban ser ignorados, sino que deben ser re-considerados como una dimensión más del objeto de estudio. Una dimensión constituida por reglas no meramente normativas, sino constitutivas, productoras del hecho linguistico o social. Esto significa no calificables como coercitivas, sino como generadoras de sentido.

Ellas implican, de acuerdo con Searle J. (1986), que hablar es comprometerse. De la misma manera, y para que sea posible una sociologia comprensiva de tipo weberiano, la acción significativa está constituida, formada por reglas, sin las cuales el sentido, "la orientación hacia otros" seria imposible. Pero, ast como una de las características esenciales del lenguaje es su aspecto creativo (Chomsky 1991), no es posible la acción sin imaginación en el plano del proyecto, de la motivación y del poder. Y para que exista un imaginario colectivo, para que las acciones sean sociales se requieren no sólo las categorias weberianas de la acción común, sino también un principio trascendental de analogía ${ }^{\prime}$, por el cual cualquier otro es también un yo. En otras palabras, existen otros egos que pueden nombrarse a sí mismos como yo en su discurso.' Esta es una condición trascendental de la constitución de la intersubjetividad en una sociedad determinada: el poder imaginar a los otros como un yo. "La imaginación tiene como competencia preservar e identificar, en todas las relaciones con nuestros contemporáneos, nuestros predecesores y nuestros sucesores, la analogía del ego" (Ricoeur 2000:210). La imaginación puede concebirse como proyecto ("querer-hacer"), por una parte, y como una expectativa ("poder-hacer"), por la otra.

No obstante lo dicho hasta aquí, esta situación no invalida las teorías de los clásicos y los objetos construidos por ellas. Considero que, en lingúistica, en sociología, así como en otras ciencias sociales, no hay conceptos "descartables", sino nociones simplificadoras de lo que -en un cierto momento histórico y según el estado de la cuestión- resultaba un objeto inabordable en todos sus aspectos. En la medida en que el conocimiento avanza, es posible incorporar niveles de análisis y profundizar aún más en la complejidad de los problemas. Esto necesariamente se hace bajo el impulso del choque con lo empírico. De ahi que sea imprescindible un movimiento constante y dialéctico entre las teorías y el mundo. Tal como sostiene Ricoeur, en la sociología comprensiva weberiana ya se hallaba implícito el principio trascendental de analogía (proveniente de Kant y de Husserl) si se tienen en cuenta su noción de acción significativa, orientada hacia el otro (otro yo que ha sido tomado en cuenta) y su cuestionamiento a la 
reificación o la apariencia de objetividad e inamovilidad dada a las instituciones. El Estado mismo es para Weber co-acción, un actuar-con de los individuos entre sí.

En suma, y en relación el concepto de lo social y (lo post social), me parece que debiéramos adoptar un pensamiento de carácter dialéctico entre dos significados posibles de sociedad, en el ámbito de la reflexión cientifica', según se trate de una perspectiva descriptiva, o bien, de una mirada crítica:

1.Si entendemos por "sociedad" lo dado históricamente en el mundo entero (no sólo en el primer mundo), es decir, los fenómenos concretos de culturas y comunidades ideológicamente diversas (aunque no coincidieran casi nunca con la noción clásica de sociedad), entonces debiéramos seguir llamando también a ésta, nuestra realidad actual, sociedad más allá de la fragmentación, de la exclusión, de la incertidumbre y otras circunstancias. En realidad, como vimos, no se trata nada más que de diferencias de grado espacio-temporales: simplemente, la sociedad no ideal del tercer mundo (fragmentada, excluida, excluyente e incierta) se ha expandido. El primer mundo está recibiendo un "boomerang" progresivo. Entonces, no tendría sentido el término post social, porque lo social existe: es "lo que es", lo dado. Desde esta perspectiva, el cientifico social deberá encarar empíricamente su objeto, describirlo, analizarlo en sus peculiaridades concretas, en la búsqueda de también concretas soluciones a los problemas. Así como en lingúística se asume que no existe "LA" lengua saussureana ("el" español, "el" inglés, etcétera), sino que ella se fragmenta en infinidad de sociolectos de origen cultural, geográfico, histórico y en diversos estilos, según las funciones que desempeñe, asi también podemos aceptar que no existe "LA" sociedad de los clásicos, con mayúsculas, y que debemos atenernos a ciertos aspectos que se nos presentan como fragmentados e inciertos. Un modelo de descripción como el de la acción trágica me parece que es adaptable a este concepto de sociedad muy alejada de la perfección y de naturaleza muy compleja.

2.El segundo significado es el de una sociedad en la que se cumple el principio de analogía de la única manera en que es posible que se cumpla: planetariamente, respecto de la humanidad entera, globalmente, tan globalmente como nos domina (sin reglas que lo contengan) el poder económico'. Este sería el momento metodológico ya no descriptivo, sino crítico cuya necesidad manifiesta De Marinis. Lógicamente, aquí tampoco tendría sentido el término post social. Más bien, debiéramos asumir que estamos aún en una etapa pre-social, tratando de construir, imaginando la utopla, en el sentido positivo del término (Ricoeur 2000), de la existencia posible de la sociedad mundial. Me parece que esta utopia y este concepto de sociedad es lo que hace posible el ejercicio crítico ${ }^{1}$

En este sentido, me parece de especial interés la reflexión que Alvite (1997) realiza acerca de la necesidad de reemplazar la noción de "solidaridad" (como "ayuda a otro sujeto de la misma situación") para -en cambio- asumir la diversidad en la subjetividad. Es decir, abandonar la concepción del sujeto único y sustancial y aceptar las diferencias subjetivas (Alvite 1997; 276). Esta posición, a mi modo de ver, fortalece nuestra propuesta del "principio de analogía" ricoureana. El único rasgo esencial que caracterizaria asi a la subjetividad seria básicamente discursivo: la posibilidad que todo hombre tiene de nombrarse a si mismo como "yo". Pero recordemos que al nombrarse no sólo dice, sino que también hace: construye su texto y al mismo tiempo necesariamente, un hecho semiótico, una acción social. En términos 
pragmático semióticos de Parret, esto equivale a pensar en un nosotros como síntoma defctico, como intersubjetividad.

\section{El homo tragicus: un modelo complejizante}

Estariamos en condiciones ahora de reconsiderar el modelo del homo tragicus de Ramos Torre, en tanto aporte metodológico a la descomplejización de lo social, desde una perspectiva pragmática. Como hemos visto, algunos de los rasgos enumerados de la acción trágica son comunes a la acción en general y también a los textos. Pero otros son especificos de lo trágico: sus caracteres dilemático, agonal y de simetría.

En este sentido, me pregunto si, de acuerdo con el tercer problema por considerar en los trabajos futuros propuestos por Ramos Torre', podríamos esbozar un proyecto de análisis de nuestra propia complejidad argentina, teniendo en cuenta algunos de estos rasgos trágicos. Por ejemplo, el dilema, la paradoja:

Abocado a decidir, el héroe se ve ante 'la discordancia trágica que le prohíbe por la misma razón por la que le obliga' (Szondii 1997:11), precipitándolo así en una situación de doble vínculo que lo atrapa en la paradoja del 'culpable si lo haces y culpable si no lo haces'. (Ramos Torre 1999:229)

Desde hace muchos afios, y particularmente en la última década, el argentino se ha visto sometido a esta situación paradójica por parte de "mandatos primarios" verbales a través de discursos de politicos, de economistas, cuando no directamente de los mismos representantes del poder financiero central (FMI, gobierno de los EEUU, etcétera). Tengamos en cuenta que en el discurso neoliberal en general, adecuadamente analizado, es posible encontrar permanentemente marcas de paradoja y doble vínculo (López 1993; López 2001).

A mi modo de ver, el paroxismo de esta situación paradojal, imposible de analizar desde modelos teóricos construidos sobre la realidad del "primer mundo", pero sí desde el que nos proporciona la "acción trágica", es del mandato primario específico que hasta ahora estábamos recibiendo para que nos convirtiéramos en ejemplares de homo prudens: la bancarización de los sueldos y del ahorro, el plazo fijo, la jubilación privada, la obra social prepaga, los distintos tipos de seguros, etc. Todo esto bajo la administración del sistema bancario nacional e internacional. Pero el fenómeno de la anomia, de la mentira sistemáticas ${ }^{1}$ y de la consiguiente corrupción -no tenida en cuenta, que yo sepa, en los análisis de los autores extranjeros (del mundo desarrollado) leídos- ha hecho que, paradójicamente, se nos impida cumplir con las obligaciones que la prudente consideración del riesgo aconseja, destruyendo la confianza implícita en todo ahorro instituido, abriendo enormes interrogantes sobre las futuras jubilaciones de las empresas (bancos) privadas, deteriorando seriamente el funcionamiento eficaz de las obras sociales. De aprendices de homo prudens pasamos entonces a ser especímenes de homo tragicus envueltos en dilemas sin solución a la vista.

Pero, tengamos en cuenta que la teoria de la paradoja nos dice que habría un modo de salvarse de la esquizofrenia y del dilema: la metacomunicación, el comunicar sobre la comunicación (incluido el contexto). A mi modo de ver, esto es precisamente lo que se ha 
intentado en estos últimos tiempos en la Argentina. Por ejemplo, en el 2001, las protestas de los diversos grupos (ahorristas, desocupados, trabajadores bancarios). A lo largo de los antos transcurridos hasta el 2007, los discursos de las asambleas barriales, de los diversos tipos de ONG con fines especificos, en tanto semiosis sociales, constituyen intentos desesperados (pero fragmentarios) de romper con el doble vínculo y con uno de los "estigmas" del hombre trágico.

Pero el peligro permanece en la posibilidad de la lucha de todos contra todos, y en la consiguiente caida en otras dimensiones trágicas. Por una parte, la acción mimética como oposición entre elementos simétricos, multiplica los conflictos entre iguales (ciudadanos contra ciudadanos; "pobres contra pobres") e implica el intento de romper con relaciones complementarias (propias del doble vínculo): gobierno (políticos) / ciudadanos; o bancos (poder financiero) / clientes.

$\mathrm{Y}$, por último, lo agonal: la no reconciliación que "lleva hasta los límites de la destrucción de las partes afectadas". (Ramos Torre 1999:229).

\section{Resumen a modo de conclusión}

A lo largo de este trabajo he intentado poner en contacto la reflexión pragmática semiótica con la propuesta metodológica del modelo de acción trágica de Ramos Torre en cuanto modelo complejizante. A través ello, se ha puesto en cuestión la vigencia del concepto de lo social y de las posibilidades semánticas de una expresión como lo post social para dar cuenta, precisamente de la complejidad actual. Para ello, he presentado algunos paralelismos entre la linguística semiótica saussureana y la sociología de Durkheim; he sintetizado algunas características fundamentales de la semiótica greimasiana clásica y actual, como una semiótica de la acción capaz de dar cuenta de la complejidad de la problemática social contemporánea y de la presencia de sus sujetos;

En sintesis, reconozco en lo social un objeto considerado de diverso modo ya sea que se trate de las ciencias sociales, de los gobiernos o de los expertos. En el marco de la reflexión sobre la ciencia, creo que tanto en sociología, como en economía y también en linguística y semiótica, deben distinguirse lo social dado y descriptible, por un lado, y lo deseado como meta desde la perspectiva crítica. En ambos casos, y por razones que ya desarrollé más arriba, me parece que el concepto de lo post social pierde sentido.

He vinculado, por fin, la relación texto/acción con el modelo de acción trágica presentado por Ramos Torre, reconociendo en este último la posibilidad de dar cuenta de la complejidad de nuestra realidad argentina, de nuestra "sociedad" (como lo social dado en estas latitudes y en estos tiempos) y de introducir un concepto de sujeto más adecuado que los hasta ahora vigentes en los ámbitos académicos y prácticos de las ciencias sociales. Hemos visto, en fin, lo que nos sucede cuando los otros nos ven como otros sin poder imaginarnos como yoes, es decir, sin incluirnos en un nosotros solidario. 